\title{
AURICULAR LOBULOPLASTY- AN AESTHETIC DAY CARE SURGICAL PROCEDURE
}

\author{
Naveen Kumar Mallineni1, Munagala Swatantra Bharathi², Thuraka Sreedhar Rao3, Pentapati Srinivas Subhash4, \\ Vadali Jayalaxmi Sushama5, J. V. Siva Priya 6
}

${ }^{1}$ Civil Assistant Surgeon, Department of Plastic Surgery, ENT Hospital, Vishakhapatnam, Andhra Pradesh, India.

${ }^{2}$ Assistant Professor, Department of Plastic Surgery, Siddhartha Medical College, Vijayawada, Andhra Pradesh, India.

${ }^{3}$ Post Graduate Student, Department of Plastic Surgery, Andhra Medical College, Vishakhapatnam, Andhra Pradesh, India.

${ }^{4}$ Post Graduate Student, Department of Plastic Surgery, Andhra Medical College, Vishakhapatnam, Andhra Pradesh, India.

${ }_{5}^{5}$ Post Graduate Student, Department of Plastic Surgery, Andhra Medical College, Vishakhapatnam, Andhra Pradesh, India.

${ }^{6}$ Post Graduate Student, Department of Community Medicine, Andhra Medical College, Vishakhapatnam, Andhra Pradesh, India.

\section{ABSTRACT}

\section{BACKGROUND}

Auricular lobuloplasty is one of the commonly done day care surgical procedure. Though surgery seems simple and lobule is small, its impact on the individual is very high because ear is one of the aesthetic parts of face. Both males and females wear attractive ornaments on their ears, for which they undergo different kinds of ear-piercing techniques. In this process, due to various reasons, ear lobule gets distorted in shape and form for which most of them seek medical advice and undergo surgical procedures to regain near normal structure of lobule. Auricular lobuloplasty is done by general surgeons, ENT surgeons and general practitioners apart from plastic surgeons. But good aesthetic results are obtained by surgeries done by plastic surgeons for the reasons of meticulous tissue handling, use of finer suture materials and post-operative follow up and care.

\section{METHODS}

50 patients who underwent auricular lobuloplasty were included in this study. Demographic characteristics, cause of surgery, presence of complications, patient satisfaction were evaluated. Surgeries were performed under local anaesthesia in 49 cases and one under general anaesthesia. Lobuloplasty was performed in 49 female patients and one male patient. Of the 50 cases of lobuloplasty, 37 were with enlarged holes, 5 tear ear, one lobule tissue loss, and 4 cases with keloid of ear lobule. There were no post-operative complications and in no case revision surgery was done.

\section{RESULTS}

Mean age was 47 years; smallest is a girl of 6 years, and oldest was 89 years old. The commonest cause for auricular lobuloplasty was enlarged ear holes, followed by ear keloids. Commonest procedure done was simple bilayer closure. It gave good aesthetic results. Patient satisfaction was evaluated by visual analogue scale.

\section{CONCLUSIONS}

Multiple surgical techniques exist for repairing ear lobule deformities. Auricular lobuloplasty is a surgical procedure that has several advantages including safety, it being a day care procedure, effectiveness and good patient satisfaction, and very minimal complications. It has great impact on feelings and beauty of a woman.

HOW TO CITE THIS ARTICLE: Mallineni KM, Bharathi MS, Rao TS, et al. Auricular lobuloplasty- an aesthetic day care surgical procedure. J. Evolution Med. Dent. Sci. 2019;8(14):1163-1168, DOI: 10.14260/jemds/2019/258

\section{BACKGROUND}

Facial aesthetics depend on the symmetry and harmony of the facial skeleton and soft tissues. The auricular lobule has an important place in face and ear aesthetics. It has c-shape lower margin, round, hanging from tragus, ante tragus and helix superiorly. It is important anatomical formation that allows women to wear accessories such as ear rings,(1,2) It has different shapes and sometimes it can attract a lot of attention on the face. It is known that Tutan Khamun, an ancient Egyptian Pharoah, had a stretched auricular lobule.(3) The use of ear ornaments by both sexes is an ancient practice in cultures worldwide. Surgical treatment of torn earlobes (TEL) resulting from ear piercing has been described from Babylon and Persia, through ancient India

'Financial or Other Competing Interest': None.

Submission 30-01-2019, Peer Review 26-03-2019,

Acceptance 01-04-2019, Published 08-04-2019.

Corresponding Author:

Dr. Munagala Swatantra Bharathi,

Assistant Professor, Department of Plastic Surgery,

Sidhardha Medical College,

Vijayawada-520008. Andhra Pradesh, India.

E-mail: bharahisreya@gmail.com

DOI: $10.14260 /$ jemds $/ 2019 / 258$

\section{(c) $($ ) $\$$}

(100 BC to $100 \mathrm{AD}$ ), to Victorian England. Stretched earlobe resulting from TEL closure was termed kákusthapáli by Sushruta Samnhita over two millennia ago (606 BC).1,2 In Africa, the Ivan and Kayan tries adorn their auricular lobules with heavy and large earrings, causing the lobules to become wide and sagging.(4) In different societies, auricular lobules are pierced for religious, cosmetic and social reasons; however, they are associated with the level of societal development. The use of ear ornaments is a multicultural practice. The lack of objective evaluations published in the national and international literature is surprising considering the high incidence of torn earlobe worldwide. Partial or complete tear is an important situation that is very common in women and leads to cosmetic deformity. In children who have traditional ear rings, are accidentally pulled or caught and forcibly get complete tears or sometimes the lobule gets partial or complete loss.

The use of earrings and heavy metals leads to sagging of ear lobule due to gravity.(5-10) It causes tearing in the ear lobule due to age, trauma, mechanical factors, intrinsic laxity of tissue and texture, faulty piercing like piercing close to edge of lobule which gets easily torn by pulls or sagging by gravity and heavy ear ornaments. 
According to the data of the American society for aesthetic plastic surgery in 2015, approximately 40,000 people per year undergo ear surgery for cosmetic purposes for ear defects because of trauma or wearing heavy earrings. Aesthetic ear interventions are the $6^{\text {th }}$ most common surgical procedures in males and $14^{\text {th }}$ most common surgical procedure in females. In India due to traditional factors female ear ornamentation more common than males. Aesthetic ear surgery is the most frequently performed at the age 3yrs to 90 years, but there has been an increase in those above 35 yrs.(11) In the present study the results of 50 patients who underwent auricular lobuloplasty for elongated ear lobules tears, enlarged holes were evaluated.

\section{Objectives of The Study}

1. To evaluate surgical procedures of auricular lobuloplasty, an aesthetic day care surgery.

2. To evaluate patient satisfaction.

\section{METHODS}

It is an observational study. Patients who underwent auricular lobuloplasty for enlarged ear holes, clefts, tissue loss or keloid ear lobules in the plastic surgery department of Visakha Institute of Medical Sciences, super specialty hospital. Visakhapatnam. between October 2016 to June 2018 were included in this study. The study was conducted in accordance with the Guidelines for Good Clinical Practice and Helsinki Declaration principles. A total of 50 patients, 49 (98\%) were females and one (2\%) male patient. There ages ranged from 5- 89 years and oldest age being 89 years and young girl 6 yrs with mean age $37 \pm 14.9$ years (table-1). Surgical consent was obtained from all patients preoperatively. All operations were performed by same surgeon under local. (General Anaesthesia for small girl of 6 yrs who is uncooperative for local procedure). The reasons for auriculoplasty and patient satisfaction were evaluated. The satisfaction of all the patients was assessed by scoring between 1 and 10 using the Visual Analogue Scale (VAS) in the post- operative period first month. The cause of auriculoplasty and patient satisfaction were evaluated. 50 cases sample is taken for trial and all conditions of ear lobule were obtained. The most simple, easy and highly acceptable procedure of auriculoplasty is observed in this study sample.

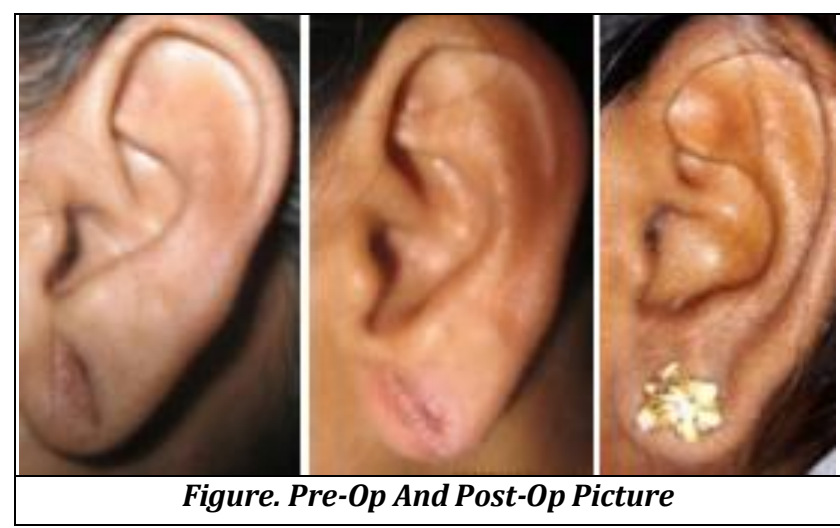

\section{Surgical Technique}

1. Enlarged ear holes:- Bilayer closure (Table -4)

After the ear cleaned and draped $1 \mathrm{ml}$ of $2 \%$ plain Xylocaine infiltrated along Side of hole in lobule and great auricular nerve blocked. Marking was done with marker pen (Fig. 1, 2). Edges of cleft will be de- epithelialized. After haemostasis is obtained with application of pressure for about 5-10 min cleft is closed in two layers separately both anterior and posterior with 5-0 Polypropylene using simple suture technique. No cautery is used for haemostasis in view of necrosis of lobule for the reason of end arteries only pressure is applied. Pressure dressing done after closure and kept for 48 hours (Fig. 2). Post operatively oral antibiotics given for 5 days with analgesics for 3 days. After $48 \mathrm{hrs}$ dressing removed and topical Mupirocin 2\% w/w ointment applied twice daily. Suture removal done on $7^{\text {th }}$ or $10^{\text {th }}$ day which is individualized. All patients given postoperative instructions to avoid sun exposure, cleansing twice daily with mild soap, Re-piercing is done after 3 months by which time adequate tensile Strength is gained. Light weight plastic pressing devises can be used after 3 weeks to avoid psychological agony to girls/women.
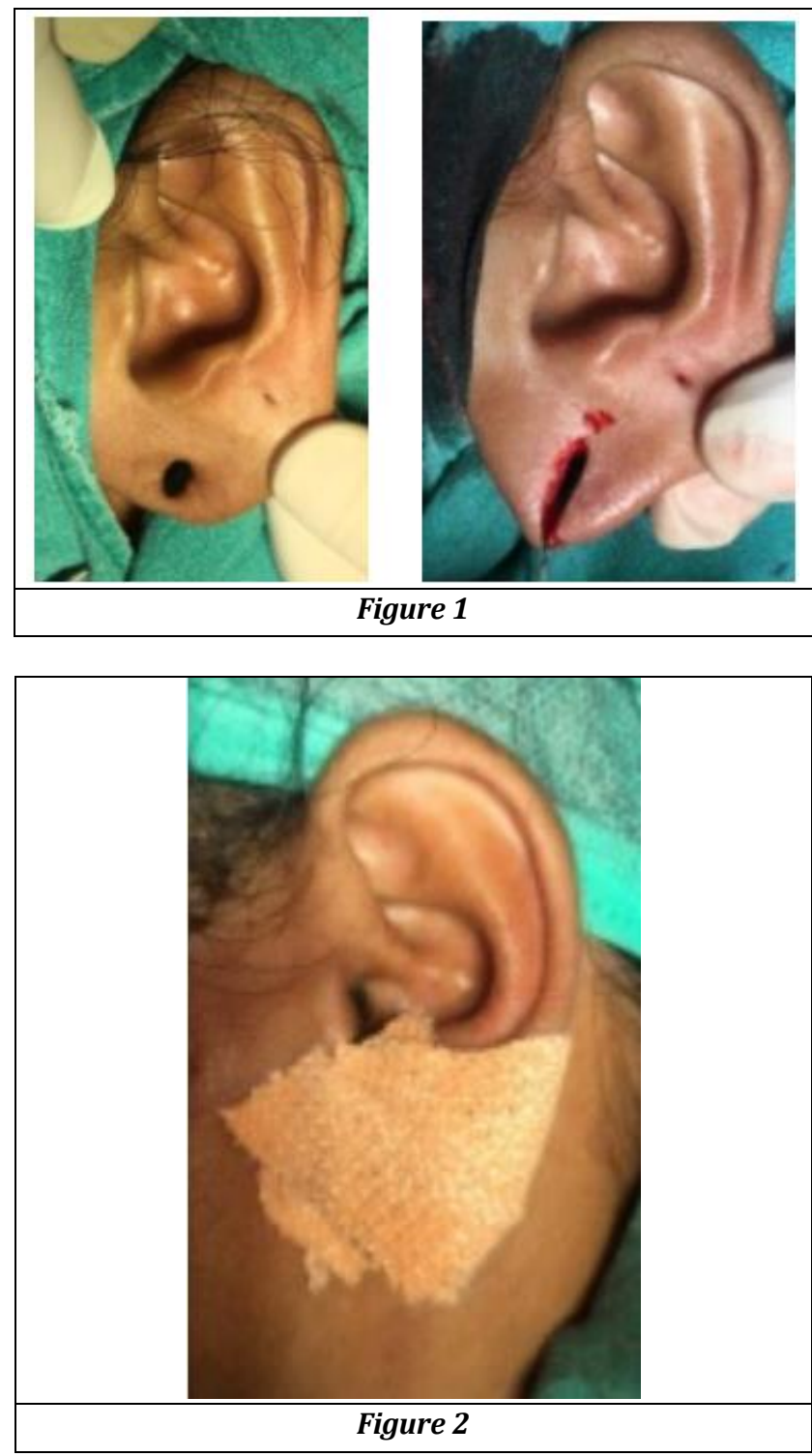

2. Lobule tissue loss- lobule loss is reconstructed in a two staged procedure by postauricular fasciocutaneous flap. A girl 6 years Presented with post traumatic tissue loss of lobule due to accidental pull of ear ring during playing. As the procedure takes time of about 1-11/2 hour and being small child reconstruction of lobule was done with 
general anaesthesia. A superiorly based post auricular flap used to recreate lobule in two stages. (Figures 3, 4, 5). This bilayer post auricular flap gives adequate pliable, soft and necessary texture of the lobule structure and is almost equal to the texture of original lobule. Even flap Replacement in lobule reconstruction is a day care procedure in case of adults which is done under local xylocaine infiltration and be can followed as outpatient.
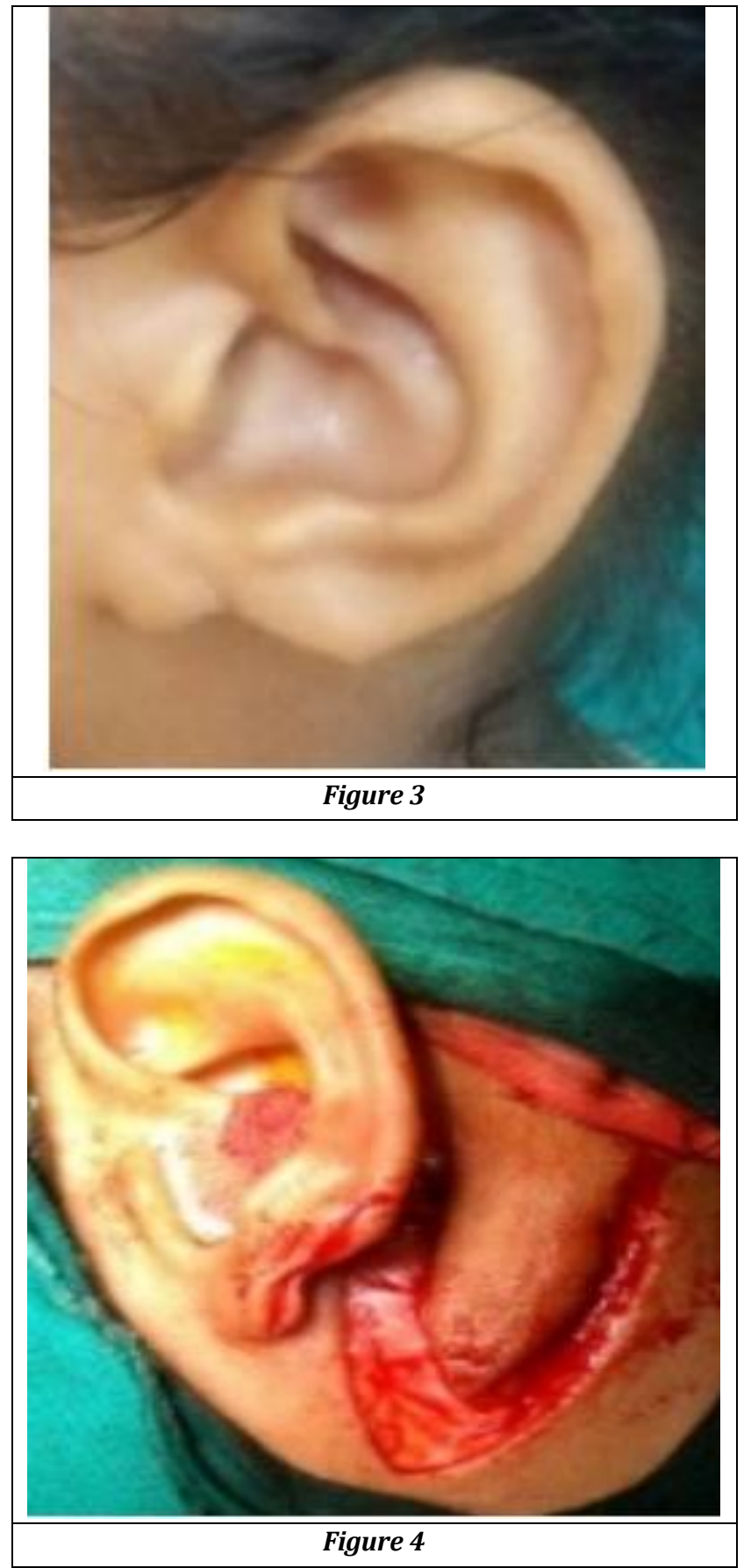

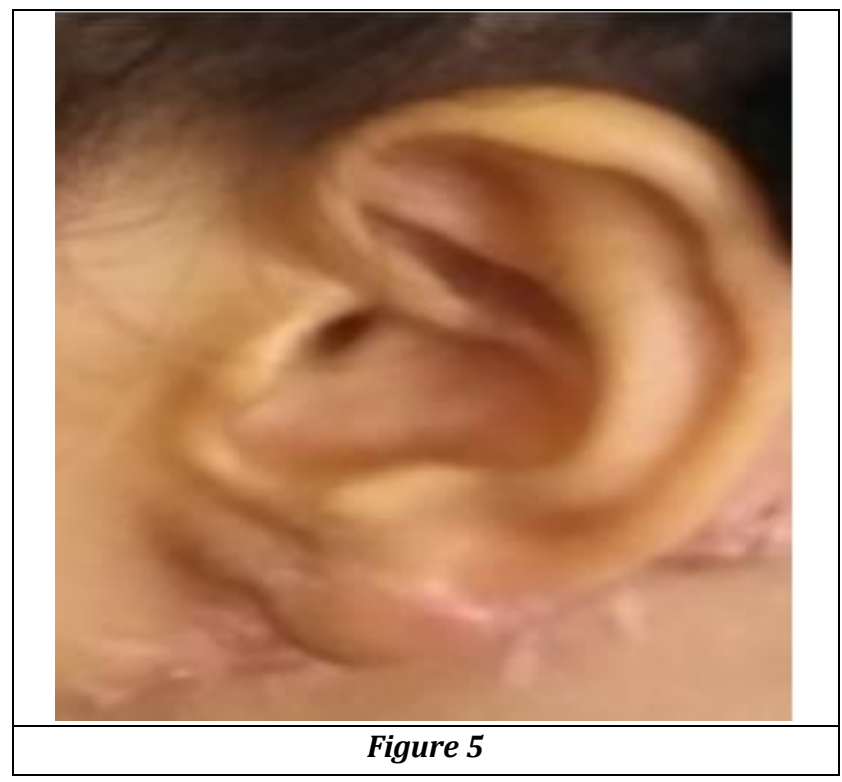

3. Keloid ear lobule- excision and z-plasty closure (Figure 6) / full thickness skin graft. (Figure 7).
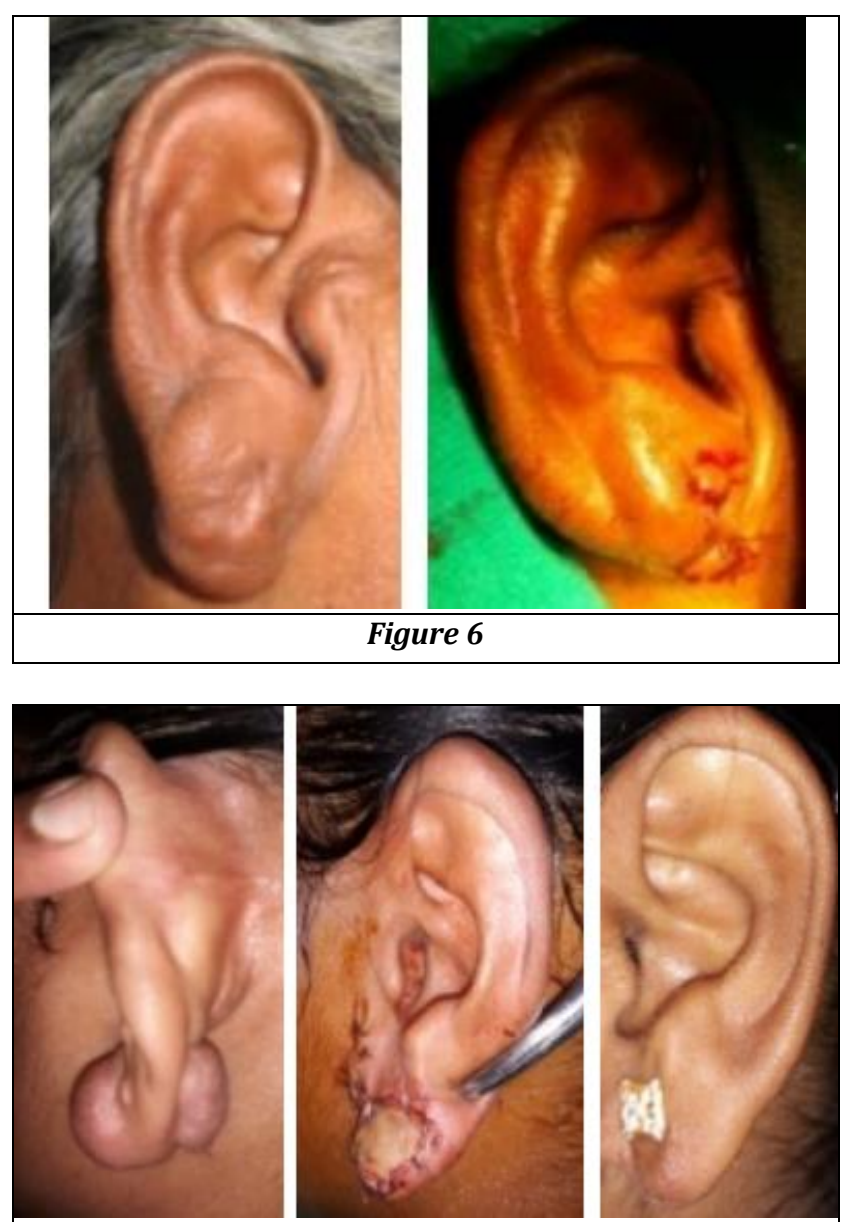

Figure 7

\section{Statistical Analysis}

Data was entered and analysed in Microsoft excel spread sheet (Version 2016). Categorical data is expressed in Simple proportions and Quantitative data were expressed using means and standard deviations. 


\section{RESULTS}

The follow up period of all patients was 6-12 months depending on the cause of defect. All surgeries performed in local anesthesia (bilayer closure) table -4 as day care procedure and one case for which a flap was required and child it was done in general anesthesia. Postoperative complications were not observed in any patients. Of the 50 cases $54 \%$ were unilateral and $46 \%$ were bilateral lobuloplasty (Table 2). The surgical outcome was consistent with the expectations of the patients. One case mild gaping observed which was managed conservatively by topical mupirocin ointment. The final result is usually a thin, neat, linear scar which generally fades away with time. The procedure takes about 15-20 minutes each side and is very affordable. (Pre and Post-op picture). Patient satisfaction becomes more important in our modern health care system. The assessment of satisfaction is difficult because it is a multifactorial item for which no golden standard exists. One of the potential methods of measuring satisfaction is by using the well-known Visual Analogue Scale (VAS). In this study, we validated VAS for satisfaction. The characteristic and satisfaction scores of all the patients according to the Visual Analogue Scale (VAS) 6-8 really good; 8-10 fantastic. Visual analogue scale in this study obtained was 48 - fantastic and 2 really good.

\begin{tabular}{|c|}
\hline Mean Age of Subjects \\
\hline $37 \pm 14.9$ \\
\hline Table 1 \\
\hline
\end{tabular}
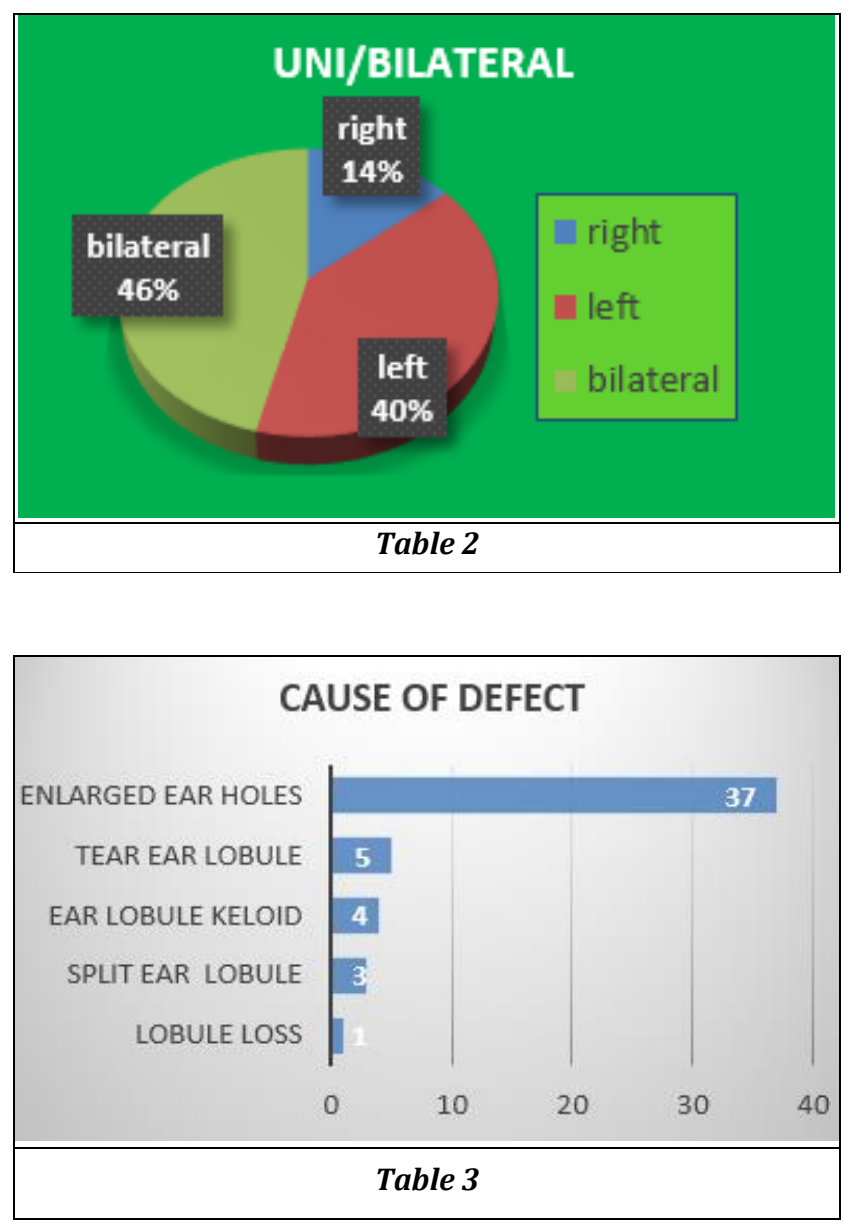
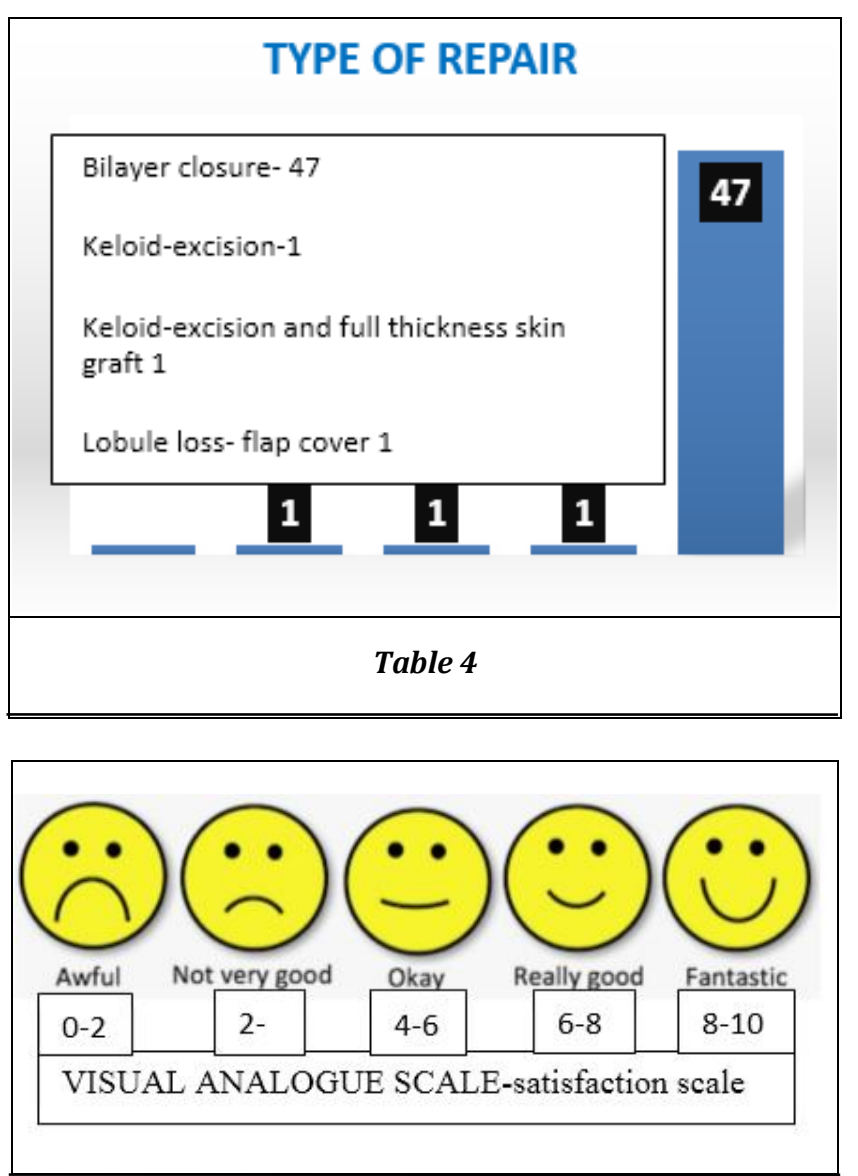

\section{DISCUSSION}

Lobuloplasty is one of the most common procedures done in outpatient basis. It is performed by a wide spectrum of surgeons ranging from general surgeon to plastic surgeon. In spite of the innumerous techniques used, the ultimate aim of the surgery is to obtain a soft supple lobule with a wellhidden cosmetic scar without the complication of recurrence. Single site local anaesthesia, scoring and paring the edges, using simple suture techniques can give good aesthetic and acceptable results. This article explains how subtle changes are still possible in common procedures like lobuloplasty to change the outcome of the results.

Auricular lobuloplasty can be performed for enlarged ear holes, congenital deformities, ageing and sagged lobule, keloids lobule, traumatic tears or auricular tumors.(12,13) Enlarged ear holes (Table 3) are the most common cause of auricular lobuloplasty and there are different classifications for auricular lobe clefts in the literature. Sharma et al.(14) divided the lobule clefts into two groups as congenital clefts and acquired clefts, and they divided acquired clefts into two groups as partial and complete clefts. Blanko-Davila and Vasconez ${ }^{(8)}$ classified the partial lobule clefts according to the distance between the original hole and the lower limit of the lobule. Boo-Chai.(15) divided the lobule defects into two groups as congenital and acquired and called the congenital clefts as "coloboma lobuli". Partial auricular clefts are usually seen bilaterally in women wearing heavy earrings for a long time. Complete lobule clefts occur in young adults as a result of wearing earrings unilaterally for a long time or as a result of trauma. $(11,13)$ Hassen ${ }^{(9)}$ reported unilateral lobule tear in $58 \%$ of the cases, bilateral lobule tear in $42 \%$, partial lobule tear in $29 \%$, and complete lobule tear in $71 \%$. Khilnani and 
Thaddanee(12) observed that $54.8 \%$ of the patients had partial clefts and $45.2 \%$ had complete clefts. In the present study enlarged ear holes were seen in 37 cases, keloids ear lobule 4, traumatic tears 5 cases. (Table 3) All are females and only one male lobuloplasty for traumatic tear. Enlarged ear holes are due to wearing of heavy ear rings, old age, sagging due to gravity and also intrinsic extremely soft texture of lobule. Compete clefts occur due to trauma.(11,13) The repair of auricular lobule defects with simple linear closure was first reported by McLaren(16) in 1954. Subsequently, different surgical techniques were described for the repair of auricular lobule defects in the literature. Tan(17) presented a "punch" technique for lobular defects smaller than $4 \mathrm{~mm}$. Relatively good results were reported with the "z-plasty" technique in 10 cases by Abenavoli.(18) Miller and Eisbach(19) documented that they made repairs using the z-plasty technique after converting the partial defects into complete defects. One of the more innovative approaches to repair partial defects is the "parallel opposed flap" technique proposed by Reiter and Alford.(20) In this technique, the anterior and posterior faces of the defect are brought close to each other and are sutured. While this technique is available for the repair of small defects, it is not appropriate for the repair of large defects.

Niamtu(4) suggested that the wound lips should be closed after the scar excision in small clefts that are in the upper two-thirds part of the auricular lobule and that the closing procedure should be performed after the partial clefts are converted into complete clefts in the lower one-third. While Hassen (9) did not excise the cleft edges in the lobule clefts, Zoltie(21) reported performing the excision leaving the apical part of the cleft intact, which would create a rectangular flap on the anterior and posterior edges of the cleft. Rich et al. noted that they were able to repair the defect by excising tissue on the posterior surface of the lobule as much as they did on the anterior surface. In small defects, Vujevich et al.(6) defined the repair of the wound edges with single continuous suture as in purse string after the defect wall was deepithelialized. In wide partial lobular defects, de la Sotta et al.(22) described the surgical technique in which the defects were closed after joining the wound orifices with wedge resection at three corners of the defect. A lot of different techniques have been described in the literature and the technique that is appropriate for the patient should be selected. Lobuloplasty procedure is individualized. Depending on the defect procedure varies. In the present study. A bilayer closure is used so that suturing is everted in a fashion which made dermal apposition good and noninversion is seen which aids healing. For healing it is the dermal apposition that is required, and closure should be without tension skin edges should be in cooptation with each other. Also gaping after suture removal is not present.

There is no consensus in the literature as to when the lobule can be punctured again after the reconstruction of the auricular clefts. Watson (23) and Vujevich et al.(6) reported that they waited for at least 6 weeks after the repair of the lobular cleft defect to re-puncture the lobule. In the present study, it was recommended that all the patients should also wait for at least six weeks to re-puncture the auricular lobule. The satisfaction rate related to the cosmetic results of lobuloplasty has been reported as $92 \%-100 \% .(18-21)$ The high level of satisfaction can be attributed to the small size of the surgical field, the simple and easy implementation of the techniques, and the low rate of complications. All of our patients were satisfied with the results of the lobuloplasty operation.

Complication rates after lobuloplasty were reported between $0 \%$ and $5 \% .{ }^{(8-21)}$ Ear piercing may result in early and late complications, despite being a low-risk procedure. The most serious complications include infections, keloid scarring, tissue avulsion, and tear ear lobule. In the present study, no complication was observed in any of the patients during the postoperative follow-up period. When choosing the best option for split earlobe repair, we must consider all factors that will influence the final outcome, such as lobe size, cleft type (Partial or total), number of orifices already existing, and a tendency to non-aesthetic scars. Considering the technical possibilities, we chose the technique that will leave the lobe more like the original, with a round not pointed shape, and the orifice that is centered. It is important to choose the technique most appropriate to each case, allowing the smallest chance of recurrence. The major techniques that do not preserve the orifice seem to be safer. However, when using the bilayer technique of repair besides the advantages of maintaining the shape of lobule there is better chance to support the earring with less chance of recurrence, and satisfactory aesthetic appearance.

\section{CONCLUSIONS}

Auricular lobuloplasty is an easy surgical office procedure. Enlarged ear holes are the most common conditions for which patients come to plastic surgeon for correction. This surgery has a low risk of complications with very satisfactory and acceptable aesthetic results. Therefore, it can be recommended to patients with lobular deformities. Auriculoplasty offered to each patient is individualized and the best option with least/absent complications is opted which in this study is bilayer closure. It has high acceptance rate both by patients and surgeons.

\section{REFERENCES}

[1] Patrocínio LG, Morais RM, Pereira JE, et al. Earlobe cleft reconstructive surgery. Braz J Otorhinolaryngol 2006;72(4):447-51.

[2] Sinha M. Techniques for correction of acquired or congenital cleft ear lobe repair. J Plast Reconstr Aesthet Surg 2006;59(9):1009-10.

[3] Hawass Z. The golden age of tutankhamun: divine might and splendour in the New Kingdom. American University: Cairo Press 2004: p. 61.

[4] Niamtu J. Eleven pearls for cosmetic earlobe repair. Dermatol Surg 2002;28(2):180-5.

[5] Suh H. Traumatic cleft earlobe repair using double triangular flap from epithelialized skin of cleft margin. J Craniofac Surg 2014;25(3):976-7.

[6] Vujevich J, Goldberg LH, Obagi S. Repair of partial and complete earlobe clefts: a review of 21 methods. J Drugs Dermatol 2007;6(7):695-9.

[7] Rich JD, Gottlieb V, Shesol BF. A simple method for correction of the pixie earlobe. Plast Reconstr Surg 1982;69(1):136-8.

[8] Blanco-Davila F, Vasconez HC. The cleft earlobe: a review of methods of treatment. Ann Plast Surg 1994;33(6):677-80. 
[9] Hassen AS. Surgical correction of cleft earlobes Hassen. Al-Azhar Assiut Med J 2016;14(2):85-8.

[10] Shen W, Cui J, Chen J, et al. Inversion of the flap at the lower ear and restoration of the flap at postauricular skin for reconstruction of the earlobe. J Craniofac Surg 2012;23(2):560-2.

[11] Cosmetic Surgery National Data Bank: Statistics, 2015. The American Society for Aesthetic Plastic Surgery website. http://www.surgery.org/media/statistics.

[12] Khilnani AK, Thaddanee R. Clinical and demographic profile of cases requiring ear lobe repair in North Gujarat. Natl J Med Res 2013;3(2):140-2.

[13] Ribeiro AA, Lourenço L, Matsuda TMHB, et al. Split earlobe repair: literature review and new technique proposal. Surg Cosmet Dermatol 2009;1(3):141-4.

[14] Sharma R, Krishnan S, Kumar S, et al. Rotation flap lobuloplasty: technique and experience with 24 partially torn earlobes. Int J Oral Maxillofac Surg 2014;43(10):1206-10.

[15] Boo-Chai K. The cleft ear lobe. Plast Reconstr Surg Transplant Bull 1961;28:681-8.
[16] McLaren L. Cleft ear lobes: a hazard of wearing earrings. Br J Plast Surg 1954;7(2):162-5.

[17] Tan EC. Punch technique--an alternative approach to the repair of pierced earlobe deformities. J Dermatol Surg Oncol 1989;15(3):270-2.

[18] Abenavoli FM. Split earlobe: repair using a half Zplasty technique. Plast Reconstr Surg 1996;98(2):372-3.

[19] Miller TR, Eisbach KJ. Repair of enlarged pierced-ear openings. Ear Nose Throat J 2005;84(5):276-7.

[20] Reiter D, Alford EL. Torn earlobe: a new approach to management with a review of 68 cases. Ann Otol Rhinol Laryngol 1994;103(11):879-84.

[21] Zoltie N. Split earlobes: a method of repair preserving the hole. Plast Reconstr Surg 1987;80(4):619-21.

[22] de la Sotta P, Paredes N, Lasalle MA. Repair of dilated earlobe due to plug piercing. Dermatol Surg 2010;36(10):1621-3.

[23] Watson D. Repair of the torn earlobe. Facial Plast Surg 2004;20(1):39-45. 